\title{
A gestão do patrimônio imaterial brasileiro na contemporaneidade
}

\author{
Sandra C. A. PELEGRINI*
}

Resumo: A problemática da sustentabilidade constitui uma prioridade quando o tema é a gestão do patrimônio cultural, e embora não haja consenso de que sua solução seja a melhor saída para garantir a preservação dos bens culturais imateriais, as expectativas nessa direção parecem otimistas. A pergunta que se coloca é: qual o alcance das políticas públicas de proteção ao patrimônio no Brasil e quais suas diretrizes essenciais? Assim, este artigo busca apreender em que medida tais políticas surgem articuladas às proposições das convenções internacionais que discutiram o tema.

Palavras-chave: Patrimônio cultural; Bens imateriais; Políticas preservacionistas.

Capoeira foi a dança da liberdade

Capoeira, pro escravo se libertar

Capoeira, do Brasil pra todo lugar

Capoeira, pra jogar e para alegrar, capoeira...

Capoeira, capoeira

Capoeira, capoeira - Professora Doutoura - Departamento de História - Centro de Ciências
Humanas Letras e Artes - Universidade Estadual de Maringá - UEM -
$87020-900$ - Maringá - PR - Brasil. Coordenadora do Centro de Estudos
das Artes e do Patrimônio Cultural (CEAPAC/UEM) e Pesquisadora do
Núcleo de Estudos Estratégicos (NEE/UNICAMP). E-mail:
spelegrini@wnet.com.br 
Dos Quilombos para academias

O mestre Bimba veio ensinar

Liberdade e igualdade aos negros

Preconceito não tem lugar, capoeira...

$\left(\right.$ Capoeira - Grito de Liberdade) ${ }^{1}$

A apreciação dos versos da canção "Capoeira - Grito de Liberdade" é oportuna neste momento, pois em 15 de julho de 2008 a "Roda de Capoeira" e o "Ofício dos seus mestres" foram registrados nos Livros das "Formas de Expressão" e no de "Saberes" como bens imateriais brasileiros.

A sonoridade produzida pelos berimbaus, atabaques, ganzás, agogôs e pandeiros somada ao acompanhamento de solistas e do coro, marca o ritmo dos jogos e a cadência dos movimentos corporais, contagia os capoeiristas e todos aqueles que observam a força e graciosidade dos partícipes da roda. Esses sons fazem aflorar sensibilidades que nos reportam para histórias de um tempo pretérito longínquo e, simultaneamente, presente nas redes de sociabilidade contemporâneas.

Essa cantiga, em particular, homenageia o Mestre Bimba, idealizador da Capoeira Regional, criada no Estado da Bahia entre 1929 e 1930. A atualidade de sua poética não deixa dúvidas sobre a inserção dessa manifestação na dinâmica cultural brasileira, tampouco sobre a alusão às raízes históricas afro-brasileiras e às práticas quilombolas. Impregnada de utopias proclamadas nas referências à liberdade e à igualdade entre as etnias em nosso país, a sua mensagem lírica aponta, entre outras questões, a importância do respeito à diversidade étnica.

A capoeira se insere num universo lúdico. É um jogo atlético de alternância entre ataques e defesas, de "caráter individual e coletivo", emergente entre "os escravos bantus procedentes de Angola, no período Colonial". Embora fortemente perseguida até as primeiras décadas do século XX, resistiu às coibições e na aurora do século XXI vem sendo 
praticada por segmentos sociais distintos e institucionalizada como "prática desportiva regulamentada" ${ }^{2}$.

Além da riqueza dos movimentos e do ritmo característico, a Capoeira Regional ou de Angola $^{3}$ catalisaram traços identitários que se tornaram signos da emancipação do homem negro na sociedade brasileira. Assim, por iniciativa do próprio Ministério da Cultura e do Instituto do Patrimônio Artístico Nacional (IPHAN), a "Capoeira" foi registrada em Salvador (Bahia) como um bem imaterial, tornando-se nacionalmente reconhecida como uma das genuínas manifestações artísticas brasileiras, envolvendo linguagens, danças e ritmos.

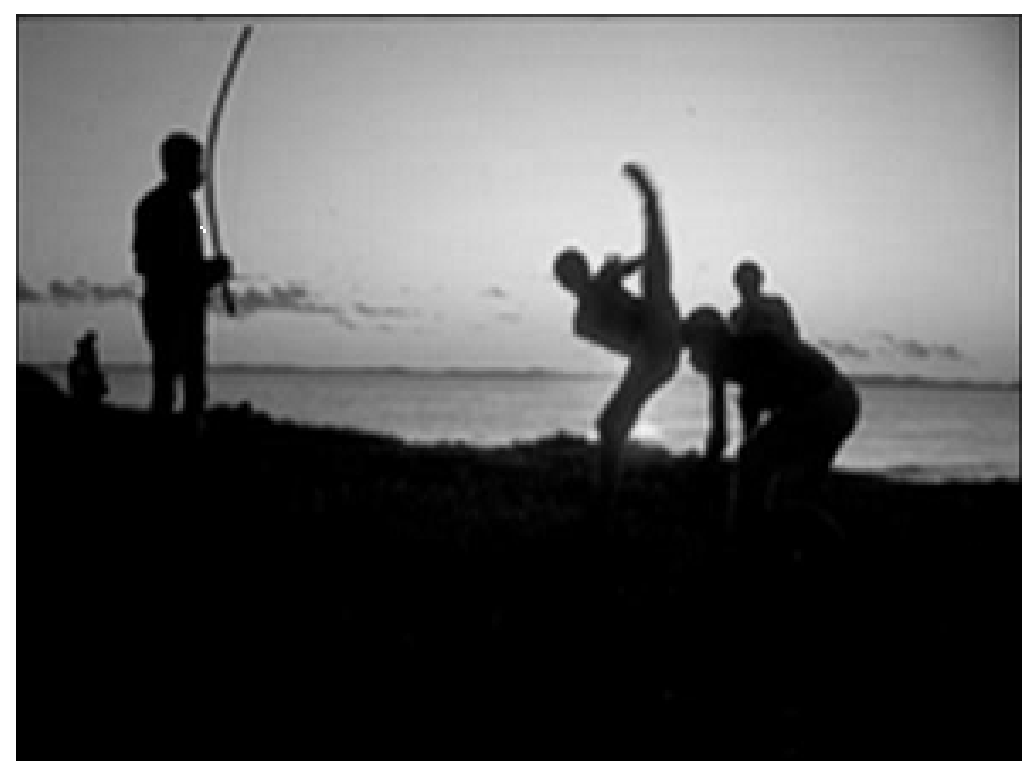

Figura 1 - Jogos de Capoeira

Foto disponível em site: http://www.portal.iphan.gov.br 
A cena do capoeirista se exercitando tendo como cenário o pôr-do-sol indica, entre outros aspectos, uma das suas peculiaridades, qual seja a busca de sintonia entre o homem e o meio. A harmonia dos movimentos e o equilíbrio são essenciais para o êxito do jogador. Dois movimentos podem ser detectados nas imagens da figura 1: a "armada" (momento em que o capoeirista lança uma das pernas para o ar) e a "esquiva de frente" (quando o seu oponente tenta escapar do golpe). Apreendida como prática tradicional incorporada ao cotidiano, a capoeira foi acautelada pelo Conselho Consultivo do Patrimônio Cultural do IPHAN ${ }^{4}$. O registro no "Livro de Expressões" e no de "Saberes" constitui importante instrumento legal de preservação do nosso patrimônio cultural imaterial, na medida em que justifica o desenvolvimento de projetos e avaliza a execução de Políticas Públicas voltadas à proteção, salvaguarda e continuidade dessa manifestação entre nós, cidadãos brasileiros de hoje, e nossas gerações futuras.

O dossiê que acompanha o processo de registro reúne os frutos de uma intrincada investigação efetuada entre os anos de 2006 e 2007 e culminou em um inventário crucial para o mapeamento das origens dessa tradição cultural popular. A complexidade do trabalho envolveu um grupo multidisciplinar de profissionais e a parceria do IPHAN com estudiosos das universidades federais da Bahia, Pernambuco, Rio de Janeiro e da Federal Fluminense. As pesquisas foram centralizadas em Salvador, Rio de Janeiro e Recife, cidades portuárias consideradas locais originários do desenvolvimento da capoeira no Brasil.

Cabe-nos lembrar que alguns especialistas do tema buscam os vínculos da capoeira com as práticas dos africanos, enquanto outros tendem a acreditar que se trata de uma luta criada no Brasil. A mesma celeuma repete-se entre os mestres Bimba (1899-1974) e Pastinha (1889-1981). O primeiro defende enfaticamente que a capoeira surgiu no território brasileiro: “[...] os negros sim, eram africanos, mas a Capoeira é de Cachoeira, Santo Amaro e Ilha de Maré Camarada" (BA). O segundo 
assevera que ela "[...] veio da África" e enfaticamente afirma: "[...] foi africano quem lutou". Parece também não haver consenso entre os capoeiristas das novas gerações: uns afirmam que essa manifestação passou a existir com a formação dos quilombos, outros salientam que teria nascido nas tribos africanas ${ }^{5}$.

A despeito dessa polêmica, o que realmente importa é o fato de a capoeira ter sido reconhecida como uma manifestação do patrimônio imaterial brasileiro, mas se buscarmos as origens históricas e etimológicas do vocábulo, descobriremos que os senhores de escravos, quando detectavam a ausência de um negro, com freqüência verbalizavam: "O negro fugiu para capoeira" 6 . Não por acaso, a acepção da palavra no linguajar tupi kapuera implica dois significados: "o que já foi roça" e "mato ralo, de pequeno porte, que nasce em lugar do mato velho"7. Talvez a segunda designação constitua uma pista para apreendermos o sentido atribuído pelos referidos senhores às práticas dos capoeiristas e quilombolas. Além disso, um dicionário da língua portuguesa dá ao vocábulo, entre outros sentidos, uma "espécie de jogo atlético tradicional no Brasil e mais violento que a savate"

Com efeito, embora tal termo expresse várias idéias, de alguma forma nos remete às origens de uma luta de resistência à escravidão e, fundamentalmente, à construção e reconstrução permanente de uma identidade étnica; e como sabemos, a salvaguarda de um bem material ou imaterial só tem sentido se esse patrimônio for reconhecido pela comunidade, se estiver relacionado ao sentimento de pertença desse grupo e incluso na sua dinâmica sociocultural.

Nessa linha de abordagem, asseveramos a necessidade da difusão do conceito de patrimônio na sociedade brasileira e de ações em prol de sua preservação. Todavia, precisamos estar atentos para não incorremos no equívoco de subestimar a capacidade e a vontade de grupos ou comunidades de defender seus próprios interesses, seus modos de viver e pensar o mundo - um olhar que sugere a compreensão de si e do outro. Mais do que isso, cumpre aprendermos os significados de posturas, 
crenças, celebrações, festas, músicas, danças, e até mesmo nos rendermos à fruição de histórias, contos e lendas - para não mencionarmos as surpresas da degustação de inusitados sabores resultantes de maneiras singulares de cozinhar e o prazer da retomada de brincadeiras não raro renegadas ou esquecidas. Assim, enfatizamos que as "tradições populares" devem ser respeitadas nas suas especificidades tanto pelos poderes públicos instituídos como pelos pesquisadores.

A experiência de estudiosos do assunto tem demonstrado que não nos cabe assumir o papel de "redentores" dos bens patrimoniais considerados dignos de nossa atenção ou

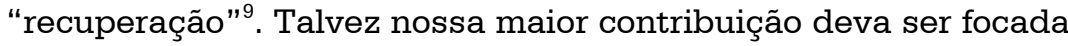
no desenvolvimento de programas de educação patrimonial e de inventários dos bens, de modo a estimular mobilizações reivindicatórias em prol da implementação de políticas públicas preservacionistas capazes de garantir a profusão de manifestações culturais populares e criar condições para sua sustentabilidade. Nesse particular, a educação patrimonial deve ser levada a sério, uma vez que pode suscitar a "consciência da preservação" e, quiçá, promover a auto-estima dos mais diversos segmentos sociais ou comunidades para que eles se percebam como cidadãos e valorizem seus bens culturais. Para tanto, fazse primordial que disseminemos as normativas nacionais e internacionais que regem as políticas públicas no Brasil.

\section{Políticas públicas de preservação no Brasil}

O êxito alcançado pelas políticas públicas de proteção ao patrimônio cultural no Brasil parece inegável, principalmente por aquelas referentes aos bens intangíveis. Vale salientarmos que a assimilação das recomendações da Organização das Nações Unidas para a Educação, a Ciência e a Cultura (e entidades afins) pelos poderes estabelecidos tem se dado de maneira muito rápida no Brasil, se comparado com outros paísesmembros dessa organização. Antes mesmo de ser proclamada a 
"Convenção Relativa à Proteção do Patrimônio Mundial, Cultural e Natural" (1972) já havia sido instituída a figura jurídica do tombamento em nosso país, por meio do Decreto-Lei n. ${ }^{\circ} 25$ (1937), e estabelecido o Serviço do Patrimônio Histórico e Artístico Nacional.

Nunca é demais lembrar que, antes mesmo da criação desse órgão, Mário de Andrade, mentor do pré-projeto que deu origem à lei do tombamento, conjeturava a relevância do estudo sobre as manifestações populares. Na contramão das idéias elitistas, que tendiam a dissociar o folclore e a cultura popular dos demais fenômenos sociais ou reduzi-los à "valorização do pitoresco", Andrade e Câmara Cascudo consideravam-nos instrumentos de conhecimento e objeto pertinente às ciências sociais. Ambos "jamais negaram as tradições brasileiras", e as apreenderam no âmbito de "uma visão dinâmica da sociedade, na qual as tradições se transformaram pela mobilidade que possuem" ${ }^{10}$.

Com efeito, alguns artigos das cartas constitucionais promulgadas na década de mil novecentos e trinta faziam menção ao "impedimento à evasão de obras de arte do território nacional" e à introdução do "abrandamento do direito de propriedade nas cidades históricas mineiras, quando esta se revestisse de uma função social"11, além da alusão à necessidade de submeter o "instituto da propriedade privada ao interesse coletivo" e de reforçar a responsabilidade do Estado para com o patrimônio e os bens culturais brasileiros ${ }^{12}$ proposições ratificadas também na Constituição de $1946^{13}$. Evidentemente, a referida agilidade no tocante ao atendimento dos princípios da "Convenção de 1972" se circunscreveu, predominantemente, aos interesses das elites brasileiras e beneficiou a proteção de monumentos, obras de arte e contíguos arquitetônicos considerados portadores de "elevado" valor para a história oficial ${ }^{14}$.

Em poucas palavras, assinalamos que, a princípio, as leis e decretos destinados à proteção e tombamento do patrimônio histórico brasileiro preteriram os bens culturais de etnias nãoeuropéias, que foram partícipes do processo de formação da 
identidade nacional. No entanto, as políticas públicas de preservação adotadas nas últimas décadas do século $\mathrm{XX}$ pautaram-se pela ampliação do conceito de patrimônio, atualmente compreendido como os bens de caráter natural, imaterial e material (móvel ou imóvel) ${ }^{15}$. A definição ampliada de patrimônio tornou imperiosa a adoção de novos instrumentos de proteção. Nesse contexto, a postura dos constituintes de 1988 foi capital, uma vez que impôs ao Estado a função de resguardar “[...] as manifestações das culturas populares, indígenas e afrobrasileiras, e das de outros grupos participantes do processo civilizatório nacional", fixando também "[...] datas comemorativas de alta significação para os diferentes segmentos étnicos nacionais" ${ }^{16}$. O reconhecimento da presença e importância de distintos grupos ou comunidades seguramente representou mais um meio de alcance da cidadania, haja vista que legitimou " $[\ldots]$ o pleno exercício dos direitos culturais e o acesso às fontes da cultura nacional".

Numa perspectiva valorativa, o patrimônio cultural do país foi definido como conjunto de bens de natureza material e imaterial (tomados individualmente ou em sua totalidade) portadores de referência à identidade, à ação, à memória dos diferentes grupos formadores da sociedade brasileira. Entre tais bens se incluem: as formas de expressão; os modos de criar, fazer e viver; as criações científicas, artísticas e tecnológicas; as obras, objetos, documentos, edificações e demais espaços destinados às manifestações artístico-culturais; sítios de valor histórico, urbanístico, paisagístico, artístico, arqueológico, paleontológico, ecológico e científico ${ }^{17}$.

Essa dinâmica acepção de patrimônio, inspirada numa percepção antropológica de cultura, marcou os reptos do "Registro de Bens Culturais de Natureza Imaterial" e concretizou-se a partir do Decreto no. 3551/2000. As novas frentes de proteção ao patrimônio nacional intangível tornaram cogente a abertura de outros quatro livros ${ }^{18}$ : 
- Livro de Registro dos Saberes e modos de fazer enraizados no cotidiano das comunidades;

- Livro de Registro das Festas, celebrações e folguedos que marcam ritualmente a vivência do trabalho, da religiosidade e do entretenimento;

- Livro de Registro das Linguagens verbais, musicais, iconográficas e performáticas;

- Livro dos Lugares (Espaços), destinado à inscrição de espaços comunitários, como mercados, feiras praças e santuários, onde se concentram e reproduzem práticas culturais coletivas ${ }^{19}$.

Novamente, o Brasil antecipou-se às disposições da Unesco: antes que esta proclamasse a "Convenção para a salvaguarda do patrimônio imaterial", em 2003, o Legislativo brasileiro já havia constituído a figura jurídica do registro como instrumento legal basilar para proteção e acautelamento dos bens intangíveis dispostos na Constituição Federal desde 1988.

No caso da capoeira, o plano de preservação decorrente do seu registro formal como manifestação cultural pressupôs a adoção de medidas capazes de oferecer suporte material à comunidade capoeirística, como, por exemplo:

- Planos de "previdência" especial para os velhos mestres;

- O estabelecimento de um programa de incentivo desta manifestação no mundo;

- A criação de um Centro Nacional de Referência da Capoeira;

- O plano de manejo da biriba - madeira utilizada na fabricação dos instrumentos - e outros recursos naturais $[\ldots]^{20}$.

Sem dúvida, as prescrições supracitadas incluem o reconhecimento dos próprios mestres como detentores de saberes cruciais para continuidade dessa manifestação cultural, bem como projetos de sustentabilidade que prevêem o manejo da biriba usada na fabricação artesanal do berimbau e de outros recursos que envolvem o meio onde vivem os capoeiristas. 
Entrementes, no Brasil, os projetos voltados à sustentabilidade pautam-se por ações que objetivam incentivar a inserção de produtos emanados de saberes tradicionais no mercado capitalista, mas para tanto determinam "mudanças técnicas, estéticas e gerenciais" de modo a adequar a produção artesanal a essas demandas ${ }^{21}$. Assim sendo, depreendemos que a implantação de programas de fomento tende a dinamizar as condições de existência das comunidades e a intensificar os processos de transformação social vivenciados por elas, além de concorrer para a alteração dos seus modos de reproduzir a vida, os costumes, os rituais. Por outro lado, o ritmo dessas mutações pode acabar por relegar ao "esquecimento e ao desuso [...] as competências e informações que esses objetos consubstanciam"22.

Contraditoriamente, enquanto esses produtos agregam valor na medida em que sejam identificados como "culturas autênticas" e as comunidades mantenham sua "cosmologia" própria, a urgência do mercado globalizado torna mais vulnerável a transmissão dos conhecimentos locais, susceptíveis às mudanças necessárias para a expansão das atividades econômicas das comunidades que são alvos de projetos de sustentabilidade econômica. Nesse sentido, a valorização do patrimônio cultural torna imperiosa a atenção dos especialistas e gestores de programas de salvaguarda em relação à sustentação das "condições materiais e ambientais necessárias à reprodução", "desenvolvimento" e manutenção do patrimônio, e também o acompanhamento das "formas costumeiras de transmissão dos conhecimentos" visando à "formação de novos executantes" 23 .

A propriedade dessas inferências pode ser observada nas ações em prol da salvaguarda do primeiro bem imaterial reconhecido no Brasil, qual seja o "Ofício das Paneleiras de Goiabeiras", registrado no Livro de Saberes (dezembro/2002); e também nas ações que inseriram o "Tambor de Crioula" no Livro das Formas de Expressão do Patrimônio Cultural Imaterial 
(junho/2007), além dos outros quatorze bens registrados até agosto de 2008.

O "Tambor de Crioula" foi catalogado pelo IPHAN como forma de expressão maranhense de origem afro-brasileira que conjuga dança circular, canto e percussão de tambores ${ }^{24}$ em louvor a São Benedito. Sob o sereno da noite nas praças ou no coração dos terreiros, os tributos ao referido santo não ocorrem em datas fixadas previamente, mas, normalmente, são realizados depois de encerrados o carnaval e os festejos de São João ou após o segundo sábado do mês de agosto, período que coincide com as "Rodas de Boi-Bumbá". Aliás, reza a tradição que essa festança seja concluída com a do "Tambor de Crioula". Conforme o levantamento efetuado pelos pesquisadores responsáveis pelo inventário desse bem ${ }^{25}$, essas duas manifestações, historicamente, ocorriam acopladas como celebrações articuladas. A "matança de boi" era e continua sendo encerrada com uma roda de tambor. Outrossim, parte dos praticantes de um festejo também o era ou é do outro.

Os depoimentos inclusos entre os documentos reunidos no inventário do "Tambor de Crioula", quando se referem às suas origens, em geral fazem alusão à época da escravidão e aos mitos criados em torno da figura de São Benedito, considerado o santo protetor dos negros. Nas reminiscências dos mais antigos e nas histórias lendárias transmitidas por gerações, o santo é recriado ora como "um escravo que foi à mata, cortou um tronco de árvore e ensinou os outros negros a fazer e a tocar o tambor", ora como um "cozinheiro do monastério que levava comida escondida em suas vestes para os pobres" ${ }^{26}$.

Seja como for, São Benedito é homenageado por percussionistas e dançarinas que compõem mais de sessenta grupos catalogados pelo IPHAN. Estas, embaladas pelo ritmo contínuo dos tambores e absortas nas "toadas" (confluência da percussão e voz dos "coreiros" ou cantadores), "tocam o ventre umas das outras", num gesto interpretado como "saudação e convite". Esse movimento coreográfico característico do bailado atinge seu ponto culminante na "punga", mais conhecida como "umbigada" 27. 
Entre as formas de proteção e gestão do "Tambor de Crioula" constam programas de incentivo aos compositores, apoio ao registro audiovisual e fonográfico, ou seja, medidas que visam a assegurar a transmissão dos saberes e o amparo aos antigos mestres. Aliás, no dia da proclamação e dos festejos que envolveram a inserção do Tambor no Livro de Expressões, houve grande confraternização entre os integrantes de vários grupos de Tambor de São Luis (Maranhão). Nessa oportunidade, alguns mestres, quando entrevistados, chamaram a atenção para o papel social do registro e sua importância no âmbito da "sustentabilidade dos grupos e das comunidades". Mestre Amaral destacou que esse registro "veio para melhorar as condições do grupo e divulgar ele em todo Brasil". Na mesma linha de interpretação, Mestre Felipe, um dos mais velhos da região, salientou que o "tambor tira(va) essas crianças (carentes) da marginalidade" 28 .

Por seu turno, o reconhecimento formal do ofício das paneleiras e da fabricação artesanal de recipientes de barro de Goiabeiras, em Vitória, capital do Espírito Santo, centrou-se nas seguintes normas:

- A valorização da tradição indígena, passada de geração a geração há cerca de 400 anos;

- A oferta de cursos práticos de capacitação para novos aprendizes, propostos pelas paneleiras mais antigas e conhecedoras do ofício;

- A conscientização da comunidade através da educação patrimonial sobre a necessidade de preservação do meio ambiente que fornece os insumos para a produção das panelas;

- Os cuidados com a extração do barro no Vale do Mulembá e do tanino coletado do manguezal (usado na coloração das panelas); 
- A difusão da importância das panelas para o cozimento das moquecas capixabas, conhecidas como um prato típico do Espírito Santo;

- A organização de uma Associação das Paneleiras de Goiabeiras (APG), uma cooperativa que assiste juridicamente as paneleiras e orienta a comercialização dos produtos artesanais com um selo de controle de qualidade.

Como apontamos, o plano de salvaguarda desse ofício envolveu ações atinentes à organização e à capacitação das paneleiras e, principalmente, à sustentabilidade deste ofício e à defesa dos direitos autorais das artesã ${ }^{29}$.

O comércio dos diversos tipos de recipientes de cerâmica continua em plena expansão no Brasil e no Exterior. Conforme os dados fornecidos pela Associação das Paneleiras de Goiabeiras, dia após dia seus produtos vêm conquistando os mercados consumidores de São Paulo, Rio de Janeiro, Pará, Rio Grande do Sul, Rondônia, Austrália, Estados Unidos e França ${ }^{30}$. O êxito do registro do Ofício das Paneleiras de Goiabeiras resultou no fortalecimento do saber-fazer dessas artesãs e incentivou outras comunidades a se organizarem para solicitar o reconhecimento de seus ofícios pelo país afora.

Esse é o caso dos santeiros do Piauí, que reivindicaram o registro da arte de esculpir em madeira. O inventário vem sendo realizado por uma equipe formada por membros do IPHAN-PI e professores da Universidade Federal do Piauí, balizado pelas diretrizes contidas no Manual de Aplicação do Inventário Nacional de Referências Culturais - IRNC (suporte metodológico produzido pelo IPHAN) ${ }^{31}$. Do mesmo modo, lembramos os trabalhadores de ofício que se organizaram na Associação dos Artesãos em Cerâmica do Poty Velho (ACERPOTI), em Teresina ${ }^{32}$.

A associação, inaugurada em 11 de novembro de 2006, no início comercializava apenas as peças produzidas pelos homens ${ }^{33}$. No entanto, motivadas pelo desafio de se inserirem no 
circuito da produção artesanal, grupos de mulheres começaram a se reunir e decidiram criar algo muito singular entre elas, quais sejam as bonecas de cerâmica, cada uma representando um tipo feminino comum na região, como rezadeiras, pescadoras, rendeiras, entre outras (Figura 2).

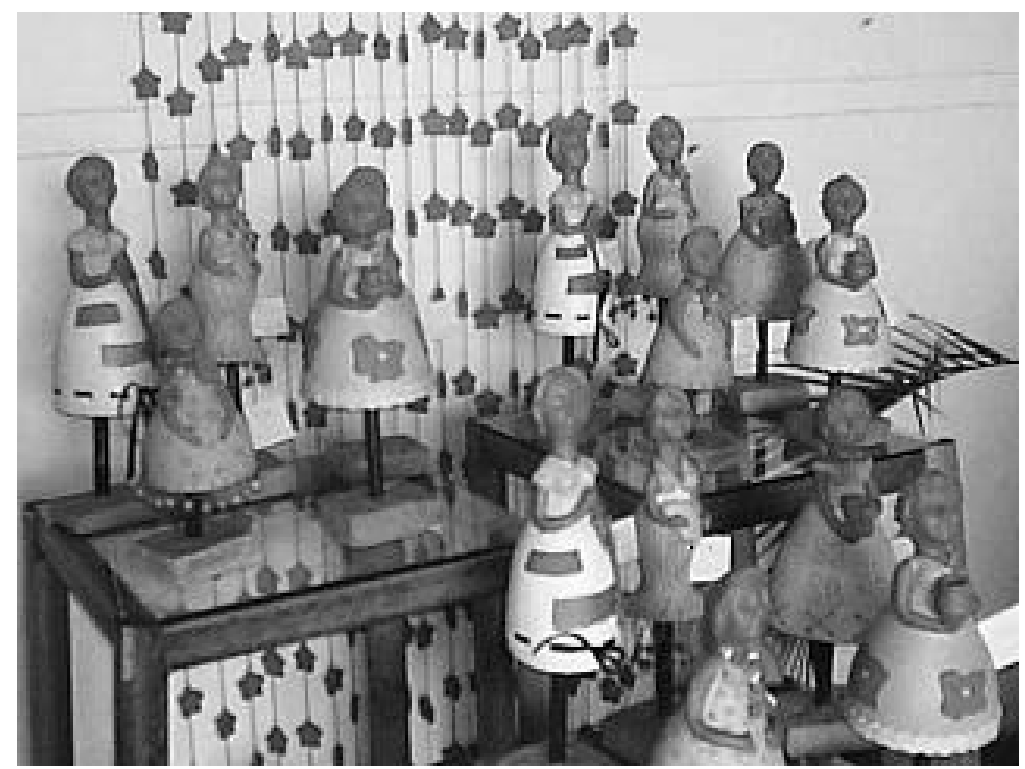

Figura 2 - Bonecas das ceramistas de Poty Velho - Teresina Piauí

Foto: Sandra C. A. Pelegrini (22.08.2008)

A associação, atualmente dirigida pelo senhor José Ribamar, vem se tornando um centro propulsor do artesanato da região. Todavia, embora a ACERPOTI tenha propiciado a criação de um pólo cerâmico inserido no circuito turístico da capital do Piauí, de antemão é possível detectarmos algumas mudanças significativas na produção e comercialização desse tipo de 
produção artesanal, que no seu processo de formação contou com o apoio da Prefeitura de Teresina e do Sebrae - PI.

A observação atenta dos modos de fazer dos ceramistas e de algumas peças, como cogumelos e tucanos coloridos, além de outros artefatos destinados à decoração de jardins, parece sinalizar alguns perigos da difusão padronizada de conhecimentos e da interferência de órgãos profissionalizantes na criatividade dos artesãos - prejuízo irreparável que pode ser identificado na homogeneização das tipologias de alguns objetos. Por essa razão, compartilhamos da preocupação de Arantes, quando este chama a atenção para a efetiva valorização do patrimônio cultural por parte dos gestores de programas de salvaguarda e para a acuidade no acompanhamento das "formas costumeiras de transmissão dos conhecimentos". Os artesãos e artesãs devem ser tratados como produtores culturais e, como tais, devem ser respeitados em sua individualidade. As singularidades de suas obras não devem ser preteridas pelas demandas mercadológicas.

Assim, consideramos decisivo o desenvolvimento de pesquisas sobre as culturas locais, uma vez que elas poderão oferecer o suporte necessário para que as comunidades não se afastem radicalmente de suas práticas originais. Nessa linha de argumentação, destacamos que uma das atribuições do IPHAN é justamente essa. Ademais, entendemos que, embora os estudiosos do patrimônio não tenham o direito de interferir, possuem o compromisso ético de tentar evitar que o apelo mercadológico resulte no cerceamento da livre expressão de saberes populares tradicionais.

Salientamos que, apesar de a globalização tender a homogeneizar as culturas, a valorização das práticas populares tradicionais impõe-se na contemporaneidade, pois essas atitudes estão imbricadas com as noções de pluralidade, de inclusão social e de cidadania ${ }^{34}$. Logo, projetos que visem à integração entre jovens e anciãos detentores de conhecimentos e técnicas ancestrais devem constituir o ponto de partida para a criação de condições propícias à transmissão dos conhecimentos e da herança cultural dos povos, e ainda, para a sustentabilidade 
e manutenção de seus bens culturais. Nessa direção, destacamos a importância de transitarmos entre documentos nacionais e internacionais de naturezas distintas, de origem européia e latino-americana, cujos conteúdos vêm balizando iniciativas no âmbito da proteção dos bens patrimoniais, além de viabilizarem a troca de experiências entre diversos países e a formulação de leis e decretos destinados à preservação.

\section{Propostas internacionais de proteção ao patrimônio imaterial}

Convenções atinentes à proteção dos bens culturais universais e tratados relativos ao "Direito Internacional" surgiram somente entre os anos 1899 e 1907. Tais acordos originaram documentos que definiram "regras universais de conduta dos Estados em períodos de guerra" ${ }^{35}$, mas se circunscreveram à tentativa de proteger a população civil e evitar ataques a hospitais e locais que armazenassem bens culturais somente nas épocas de conflitos armados internacionais.

Até meados do século XX constava da doutrina relativa ao "Direito Internacional" que a proteção dos bens culturais adotasse os seguintes preceitos: evitar o saque dos bens culturais e conservá-los durante os conflitos armados, e ainda, definir normas visando à proteção de tais bens em tempos de paz, por meio de políticas permanentes de "seleção, classificação, conservação e restauração". Esses princípios foram esboçados na "Convenção para a proteção dos bens culturais em caso de conflito armado - Convenção de Haia" (1954) e na "Convenção relativa à Proteção do Patrimônio Mundial, Cultural e Natural" (1972), respectivamente ${ }^{36}$.

Os documentos supracitados foram sancionados sob os auspícios da Organização das Nações Unidas para a Educação, a Ciência e a Cultura, criada após a II Guerra Mundial. Aliás, a destruição e o caos causados por esse confronto bélico 
mobilizaram a comunidade internacional e suscitaram a criação de organizações com o intuito de evitar conflitos e intermediar cizânias. Criada no contexto da denominada "Guerra Fria", a Unesco assumiu inúmeras atribuições, entre elas a defesa do patrimônio mundial da humanidade. Em vista disso, a partir da segunda metade da década de 1940, esse órgão passou a realizar encontros entre políticos e estudiosos dos mais diversos países do mundo com o objetivo de discutir estratégias pacíficas de desenvolvimento mundial. Infelizmente, nem todos os Estados se renderam aos seus ditames.

Assim, somente cerca de vinte e sete anos após o início das negociações, foi consolidada a "Convenção Relativa à Proteção do Patrimônio Mundial, Cultural e Natural" - um acordo que conseguiu congregar apenas 148 países. Apesar das dificuldades em fazer convergir interesses conflitantes, devemos reconhecer que as recomendações dessa instituição, somadas às sugestões de outros órgãos independentes, vêm formulando normativas cruciais em defesa do patrimônio cultural e natural da humanidade, influenciando a formulação de políticas públicas no campo da educação, do patrimônio e da cultura.

Por certo, a "Carta de Haia" (1954) representa um marco na trajetória da Unesco. De todo modo, a proteção aos bens culturais ainda se manteve, preponderantemente, circunscrita ao patrimônio natural, aos bens edificados, monumentos e obras de arte no continente europeu (ou relacionadas a ele). A ampliação da acepção de patrimônio propiciou o surgimento de reivindicações no sentido da proteção de valores identitários antes ignorados.

As utopias de uma sociedade mais humana e a revisão de arquétipos de comportamento e poder nos anos sessenta do século XX fortaleceram os enfoques antropológicos do patrimônio, agora tomado como testemunho do cotidiano e da concretização do insólito. Nessa direção, alargaram-se os fundamentos que norteavam a seleção dos bens e o sentido da preservação propugnada pela Unesco, alcançando não somente monumentos suntuosos representativos do ponto de vista dos poderes hegemônicos, mas também construções mais simples e 
integradas ao dia-a-dia das populações e, mais recentemente, os bens culturais de natureza intangível ${ }^{37}$. Esse é o caso da proclamação do "Espaço cultural de San Basílio" (Colômbia); das "Tradições pastoris e carros de boi" (Costa Rica); da "Dança tradicional Cocolo" (República Dominicana); da "Arte têxtil Taquile" (Peru), do "Samba de roda do Recôncavo Baiano (Brasil), entre outros, como bens inclusos na "Lista das Obras Mestras do Patrimônio Oral e Imaterial da Humanidade" (2005).

A emergência de lutas das minorias religiosas, sexuais e étnicas provocou profundas transformações e repercutiu nos modos de entendermos o patrimônio. A "Declaração do México" (1982), por exemplo, assimilou novos critérios de avaliação e preservação dos bens culturais e, conseqüentemente, sugeriu a expansão do conceito de cultura e monumento, outrora impressos na "Convenção Relativa à Proteção do Patrimônio Mundial, Cultural e Natural" (1972). Não por acaso, os representantes da Bolívia junto à Unesco passaram a pleitear maior atenção às manifestações relativas à "cultura tradicional e popular". Nos anos subseqüentes, as demandas em defesa dos bens relacionados à cultura imaterial provocaram pressões no sentido do reconhecimento jurídico desse patrimônio.

A partir de 1980, outros órgãos ou organizações passaram a abraçar a causa das culturas tradicionais não-ocidentais. A "Conferência Mundial sobre as políticas culturais" (1982), realizada em Mondiacult (México), sob a responsabilidade do Conselho Internacional de Monumentos e Sítios (ICOMOS), assinalou com veemência a importância da relação entre o patrimônio e a identidade cultural, definindo esta última nos seguintes termos: "[...] uma riqueza que dinamiza as possibilidades de realização da espécie humana ao mobilizar cada povo e cada grupo a nutrir-se de seu passado e a colher as contribuições externas compatíveis com a sua especificidade e continuar, assim, o processo de sua própria criação". Tal inferência corroborou para reafirmar os princípios "pluralismo cultural"38.

Podemos considerar que o documento conclusivo dessa conferência abriu espaço para a emergência de outras 
sensibilidades, capazes de valorizar a troca de experiência e oferecer um pouco mais de visibilidade e respeito aos modos de viver e sentir distintos da civilização ocidental. Ademais, a "Conferência de 1982" lançou os preceitos que embasariam a proteção de bens intangíveis na atualidade, pois não se furtou a difundir uma acepção mais abrangente e capaz de identificá-los como "conjunto dos traços distintivos espirituais, materiais, intelectuais e afetivos" que balizavam "uma sociedade e um grupo social", suas manifestações artísticas e lingüísticas, suas formas de conduzir a existência e determinar princípios éticos, crenças e tradições. Essas recomendações adquiriram maior peso político na "Recomendação sobre a salvaguarda da cultura tradicional e popular" (1989), documento-síntese da 25a Reunião da Conferência Geral da Unesco, e também no "Informe da comissão mundial de cultura e desenvolvimento" (1996) ${ }^{39}$.

Cabe ressaltar que a Conferência de $1989^{40}$ destacou a cogente necessidade de respeitarmos a cultura tradicional e popular em sua dinâmica, no seu permanente processo de mutação e ressignificação de valores. Por essa via, asseveravase que "a conservação da documentação relativa às tradições da cultura tradicional e popular devia privilegiar a percepção se tais práticas continuavam ou não sendo utilizadas ou se haviam passado por transformações", e que cabia aos pesquisadores ou às gerações futuras interessadas na manutenção das tradições aferirem as adequadas políticas preservacionistas.

Em outros termos, esses indicativos implicaram que cada Estado-membro promovesse pesquisas para identificar as culturas tradicionais e populares no âmbito regional e nacional, e ainda, incentivasse a realização de inventários nacionais de instituições interessadas nessa temática e sua inclusão em listas de registros regionais e/ou mundiais. Encadeadas a medidas devotadas ao desenvolvimento de sistemas de registro, catálogos ou guias de compilação, essas instruções de 1989 realçaram o entrecruzamento do "direito cultural" com a concepção de cultura assentada nas proposições da Antropologia. 
A cultura tradicional e popular passou a ser abordada como um conjunto de criações fundadas na tradição de grupos ou indivíduos que correspondiam a uma dada "identidade cultural e social", expressa por meio da "língua", "literatura", "música", "dança", "jogos", "mitologias", "rituais", "costumes", "artesanato", "arquitetura e outras artes", instituídas através de valores transmitidos ancestralmente ${ }^{41}$.

A despeito da prodigiosa contribuição das reflexões contidas nas recomendações da "Conferência de 1989", elas precipitaram algumas suscetibilidades que seriam percebidas pelos estudiosos do patrimônio imaterial somente no início do século XXI. De fato, esse documento afirmou o caráter "evolutivo" da cultura e inadvertidamente retomou referenciais que embasavam a arcaica hierarquização das culturas, fruto do cotejamento com a cultura ocidental. Além disso, remeteu a certa suspeição quanto à validade dos registros da cultura ou das expressões culturais populares.

Ora, a cultura, seja ela erudita ou popular, não pode ser avaliada como um conjunto preciso de dados que se conservam incólumes, haja vista que agregam significados e incorporam práticas ao longo dos tempos. Não obstante, cumpre-nos ressaltar que essas assimilações de valores e/ou reelaborações são recorrentes na dinâmica social das comunidades em que se inserem $^{42}$.

Nessa linha de abordagem, consideramos imprescindível a análise da "Convenção para a salvaguarda do patrimônio imaterial", firmada em 17 de outubro de 2003. Ela vem sendo apontada pelos especialistas como um dos documentos internacionais mais significativos na esfera da proteção dos bens intangíveis, porque suas recomendações vêm norteando as políticas em defesa dos bens culturais de natureza intangível em todo o mundo ${ }^{43}$.

Notamos que, no seu conjunto, a "Convenção de 2003" toma como pressuposto a alteridade entre as culturas e o tempo, e ao fazê-lo, admite que as transformações ocorridas no cerne das comunidades e no meio ambiente interferem nos modos de 
vida dos povos e na sua história. Não obstante, a despeito do valor dos princípios mencionados, a própria Convenção de 2003 reconhece os limites dessa assertiva. Admite que os contínuos processos de transformação social e a globalização, por um lado viabilizam "um diálogo renovado entre as comunidades", mas, por outro, suscitam a "intolerância" e condições de desenvolvimento díspares que repercutem na "deterioração, desaparecimento e destruição do patrimônio cultural imaterial", porque a maior parte das comunidades ou minorias étnicas carece de meios eficazes para a promoção da salvaguarda de seus bens culturais.

Sob a ótica do documento, essa questão não invalida a amplitude atribuída ao conceito de diversidade cultural e ao sentido de pertença e identidade desses grupos, muito pelo contrário, a compreensão das transformações das relações entre o homem e o meio e suas maneiras de produzir cultura reforça o respeito à pluralidade cultural ${ }^{44}$. Ainda assim, o documento não explicita quais seriam os critérios para o reconhecimento do patrimônio imaterial, apenas sugere que o acautelamento de bens de natureza intangível deva se ajustar aos "instrumentos internacionais de direitos humanos", estimular o "respeito mútuo entre comunidades, grupos e indivíduos" e pautar-se pelo "desenvolvimento sustentável" 45

A "Convenção de 2003", no seu artigo segundo, recomenda a criação de um "Comitê Intergovernamental para a Salvaguarda do Patrimônio Cultural Imaterial"46, o investimento na identificação, catalogação e recuperação dos bens intangíveis e na "educação formal e não-formal" com vistas a garantir a transmissão dos conhecimentos às gerações futuras. No artigo terceiro, estabelece que as disposições presentes na Convenção de 2003 não podem "modificar o estatuto" da "Convenção do Patrimônio Mundial" (1972). Além disso, reitera que o Comitê Intergovernamental para a Salvaguarda do Patrimônio Cultural Imaterial definiria os "critérios e modalidades" pelos quais se daria a certificação dos bens que pleiteassem a inclusão na "Lista representativa do patrimônio cultural imaterial da humanidade". 
Em decorrência da tentativa de delimitar a relação dessa convenção com outros instrumentos internacionais, a "Convenção de 2003" parece deixar subentendido que, apesar de imprimirem uma visão valorativa das "tradições e expressões orais", os critérios de seleção da "Convenção de 1972" continuam válidos. Assim sendo, a ênfase no "excepcional valor universal" do bem imaterial não estaria ratificando juízos de valor compatíveis apenas com a cultura ocidental?

Se cogitarmos que seja essa a postura assumida pela Unesco, como apreenderíamos sua suposta disposição de selecionar e promover "os programas, projetos e atividades de âmbito nacional, sub-regional ou regional para a salvaguarda do patrimônio imaterial", considerando-se as "necessidades especiais dos países em desenvolvimento", expressa no artigo 18, da Convenção de 2003?

Podemos arriscar-nos a dizer que, numa tentativa de aparar possíveis arestas deixadas pela "Convenção de 2003", a Unesco priorizou o reconhecimento das mais distintas expressões culturais na "Convenção para proteção e promoção da diversidade cultural" (2005) ${ }^{47}$. Apesar de sugerir a valorização de estratégias de defesa de patrimônios locais, não enfrentou um problema basilar, qual seja o da indústria da cultura no âmbito da economia globalizada ${ }^{48}$.

\section{Notas finais}

Enfim, longe da pretensão de apontar soluções, propusemo-nos a ponderar acerca dos impasses que envolvem os reptos da proteção e salvaguarda dos bens culturais imateriais. Ainda assim, talvez o que realmente pudemos detectar através da análise dos documentos e recomendações da Unesco diga respeito à sua tentativa de retificar a perspectiva monumentalista atribuída ao patrimônio desde meados do século XIX. 
Nessa linha de abordagem, seria ingênuo de nossa parte imaginar que as alterações processadas nos paradigmas que informavam as normativas internacionais ocorreram de maneira espontânea. Muito pelo contrário, elas resultaram das pressões exercidas pelos representantes de culturas minoritárias de Estados signatários da referida organização, a começar pelas reivindicações de reconhecimento da cultura tradicional e popular propugnadas pela Bolívia em meados da década de 1980.

Afinal, a memória, impregnada nas mais diversas tipologias patrimoniais, como toda e qualquer experiência humana, revela-se um "campo minado" por embates sociais. No caso da preservação dos bens imateriais no Brasil não seria diferente. Como procuramos demonstrar, paulatinamente, as mais distintas comunidades com suas respectivas manifestações culturais vêm adquirindo visibilidade e reconhecimento social.

\section{Agradecimentos}

Nossa gratidão aos professores: Dr. Pedro Paulo Funari (UNICAMP), Dra. Zélia Lopes da Silva (UNESP-Assis), Dra. Margarida Maria de Carvalho (UNESP-Franca), Dra. Áurea Pinheiro (UFPI), Dr. Fernando Campos e Dr. José Carlos Calazans (Universidade Lusófona - Lisboa), pelos profícuos colóquios e contribuições instigantes. Contudo, as idéias aqui expressas são de inteira responsabilidade da autora.

PELEGRINI, Sandra C. A. The administration of the Brazilian nonmaterial heritage in the contemporary world. História, v.27, n.2, p.145-173, 2008.

Abstract: The problems of sustainability are made a priority when the subject is the management of cultural heritage. However there is no consensus as to whether this solution is the best way to guarantee the preservation of its intangible cultural 
assets. Furthermore the expectations in this direction seem optimistic. The issue in question is: how far do public policies reach in their protection of the Brazilian heritage? And, what are their essential guidelines? Thusly, this article tries to comprehend how such policies appear in conjunction with proposals of international conventions devoted to this subject.

Keywords: Cultural heritage; Intangible assets; Preservation policies.

\footnotetext{
NOTAS

${ }^{1}$ Não foi possível identificar a data e a autoria dessa música. Tal fato é muito comum, pois as canções passam por constantes processos de recriação coletivos, raramente preocupados com esse tipo de registro.

2 SANTOS, L. S. Capoeira. Uma expressão antropológica da cultura brasileira. Maringá: PPG/UEM, 2002, p. 34.

${ }^{3}$ O Mestre Bimba, Manoel dos Reis Machado, é reconhecido como o criador do estilo de Capoeira Regional (a mais estilizada), enquanto o Mestre Pastinha, Vicente Ferreira Pastinha, é tido como o fundamental representante da Capoeira Angola definida como a mais original ou primitiva. Sobre as práticas dos negros quilombolas consultar: REGO, W. Capoeira Angola: ensaio sócio-etnográfico. Salvador: Itapuã, 1968; D' AQUINO, I. Capoeira: strategies for statey power and identity. EUA, 1983. Tese (Doutorado), University of Illinois; FUNARI, P. P. e CARVALHO, A. V. Palmares, ontem e hoje. Rio de Janeiro: Jorge Zahar Ed., 2005.

4 Esse Conselho é composto por vinte e dois representantes de entidades e da sociedade civil e é responsável pela deliberação a respeito dos registros e tombamentos do patrimônio nacional.

${ }^{5}$ SANTOS, L. S. Capoeira. Uma expressão antropológica da cultura brasileira. Op. cit, p. 34-35.

6 Sobre o assunto, consultar literatura especializada: CHALHOUB, Sidney. Visões da Liberdade: uma história das últimas décadas da escravidão na Corte. São Paulo, Cia. das Letras, 1994; FRANCO, Maria Sílvia de Carvalho. Homens livres na ordem escravocrata. São Paulo, Editora da UNESP, 1997 (4ª . edição); ALENCASTRO, Luiz Felipe de. O Tratado dos Viventes: Formação do Brasil no Atlântico Sul (séculos XVI e XVII). São Paulo: Companhia das Letras, 2000; AZEVEDO, C. M. M. 
Onda negra, medo barco: o imaginário das elites - século XIX. São Paulo: Annablume, 2004 (2a . Edição).

7 WEISZFLÖG, Walter. Michaelis: Moderno Dicionário da Língua Portuguesa. São Paulo: Companhia Melhoramentos, 1998.

${ }^{8}$ A savate é definida como uma "luta francesa a pontapés, segundo certas regras". Cf. Ferreira, A. B. H. Novo Dicionário Aurélio. Rio de Janeiro: Nova Fronteira, 2002.

${ }^{9} \mathrm{O}$ antropólogo José Reginaldo Santos Gonçalves debate essa questão nos livros: GONÇALVES, J. R. S. A retórica da perda. Os discursos do patrimônio cultural no Brasil. Rio de Janeiro: Editora UFRJ/MinCIPHAN, 2002, 148 p.; GONÇALVES, J. R. S. Antropologia dos objetos: coleções, museus e patrmônios. Rio de Janeiro: MinC. - IPHAN - DEMU, 2007, $256 \mathrm{p}$.

${ }^{10}$ Apesar de algumas discordâncias, Vânia de Vasconcelos Gico indica que Andrade e Cascudo estavam empenhados em compreender a realidade brasileira a partir dos estudos da cultura não-erudita. GICO, V. V. Vasconcelos. Câmara Cascudo e Mário de Andrade: uma sedução epistolar . Revista do Patrimônio Histórico e Artística Nacional, São Paulo, n. 30, pp.111 - 127, 2002, p.116.

${ }^{11}$ BRASIL. Constituição Federal Brasileira, 1934.

${ }^{12}$ BRASIL. Constituição Federal Brasileira, 1937.

13 Sobre o assunto consultar: KERSTEN, M. S. A. Os rituais do Tombamento e a escrita da História: Bens Tombados no Paraná entre 1938 - 1990. Curitiba: Editora da UFPR, 2000; PELEGRINI, S. C. A. O patrimônio cultural no discurso e na lei: trajetórias do debate sobre a preservação no Brasil. Patrimônio e Memória - Revista Eletrônica, v. 2, n. 2, p. 1-24, Assis - São Paulo: UNESP - FCLAs - CEDAP, 2006, p. 13.

14 Esses valores distintivos dos exemplares a serem preservados atende aos critérios normativos da "Convenção Relativa à Proteção do Patrimônio Mundial, Cultural e Natural" (1972), chancelada pela Unesco. Evidentemente, como destacou a historiadora Déa Fenelón desde 1992, tais bens muito bem representavam a história oficial e a memória das elites detentoras de posses de monumentos e edifícios, em geral de propriedade do Estado e da Igreja Católica. FENELON, D. R. Políticas Culturais e Patrimônio Histórico. In: CUNHA, Maria Clementina Pereira (org.) O Direito à Memória: patrimônio histórico e cidadania. São Paulo, Departamento do Patrimônio Histórico, 1992, p. 29-33. 
${ }^{15}$ PELEGRINI, SANDRA C. A. World Heritage Sites: Types and Laws. In: PEARSALL, D. M. Encyclopaedia of Archaeology. Oxford: Elsevier Ltd, 2007. MS number 323, pp. 2215-2218.

16 Conforme disposto, respectivamente, no primeiro e segundo parágrafos do artigo 215, da Carta Magna de 1988. BRASIL. Constituição Federal Brasileira, 1988.

${ }^{17}$ Conforme disposto no artigo 216, da Constituição Federal Brasileira (1988). Op. cit.

${ }^{18} \mathrm{Em}$ 1937, os primeiros livros instituídos foram os seguintes: Livro do Tombo Arqueológico, Etnográfico e Paisagístico; Livro do Tombo Histórico; Livro do Tombo das Belas Artes e Livro das Artes Aplicadas. 19 BRASIL. Decreto no. 3551, 2000. Para aprofundar o tema ver: O Registro do Patrimônio Imaterial. Dossiê final das Atividades da Comissão e do Grupo de Trabalho do Patrimônio Imaterial. Brasília: IPHAN, 2000, $208 \mathrm{p}$.

${ }^{20}$ Cf. Informações da Assessoria de Comunicação Iphan - Monumenta, disponíveis no site: http//www.portal.iphan.gov.br. Acesso em jul/2008.

${ }^{21}$ Para maiores detalhes sobre o assunto ver: ARANTES, Antônio. O patrimônio imaterial e a sustentabilidade de sua salvaguarda. DaCultura, ano IV, n. 7, pp. 9-14. Disponível em site: http://www.funceb.org.br/revista7/04.pdf. Acesso em ago/2007.

${ }^{22}$ Ibidem, p. 12-13.

${ }^{23}$ Ibidem, p. 14.

24 Sob a ótica dos especialistas, o gestual das dançarinas, seus movimentos corporais e a polirritmia dos tambores o aproximam de algumas características do "samba de terreiro" e "partido alto" (modalidades do samba carioca). Além disso, o Tambor de Crioula pode ser articulado a outros bens já registrados como patrimônio imaterial brasileiro, como o Jongo e o Samba de Roda do Recôncavo Baiano.

25 Entre os pesquisadores constam Valderina Barros, Christiane de Fátima Silva Mota, Renata dos Reis Cordeiro, Sislene Costa e Bartolomeu Mendonça. RAMASSOTE, R. M. (org.). Os Tambores da Ilha. Disponível no site: http://portal.iphan.gov.br/portal/baixaFcdAnexo.do?id=719. Acesso em fev./2008.

${ }^{26}$ Parece não existir nos depoimentos recolhidos pela equipe do IPHAN uma convergência quanto às origens ancestrais do Tambor, mas sim o 
relato de histórias e memórias específicas dos grupos catalogados. RAMASSOTE, R. M. (org.). Os Tambores da Ilha. Op. cit.

${ }^{27}$ Ibidem.

${ }^{28}$ PELEGRINI, S. C. A. e FUNARI, P. P. O que patrimônio cultural imaterial. São Paulo: Brasiliense, 2008, p. 102.

${ }^{29}$ Ibidem, p. 76.

${ }^{30}$ Dados inseridos na documentação referente ao processo de registro do Ofício das Paneleiras estão disponíveis no site: http://www.portal.iphan.gov.br. Sobre o assunto consultar também: PELEGRINI, S. C. A. e FUNARI, P. P. Op. Cit.

${ }^{31}$ O grupo conta com a participação da Dra. Áurea da Paz Pinheiro, da UFPI.

32 Segundo Ariane dos Santos Lima e Marluce Lima de Morais (bolsistas do Programa de Educação Tutorial do Curso de História da UFPI), o bairro Poty Velho "é um local de memória no contexto da história da cidade de Teresina, por ser o primeiro espaço de ocupação que deu origem a atual capital do Piauí"(concebida em 1852). LIMA, A. S e MORAIS, Marluce Lima. A história e a memória dos arte-ceramistas de Teresina - Piauí. In: I CONGRESSO INTERNACIONAL DE HISTÓRIA E PATRIMÔNIO CULTURAL, 1, 2008. Anais do Congresso Internacional de História e Patrimônio Cultural. Memória, ensino e bens culturais. Teresina/Piauí: UFPI e Anpuh-PI, 2008, pp. 1-12.Convém lembrarmos que a elaboração desse artigo contou com a orientação dos professores Dra. Áurea da Paz Pinheiro e Ms. Raimundo Lima.

33 Pedro Ferreira Lima, secretário municipal de Desenvolvimento Econômico de Teresina-PI, salientou a importância da parceria firmada pela Prefeitura com o Governo do Estado, Sebrae e Associação dos Ceramistas do Poty Velho para a concretização do "Pólo Cerâmico" que visa a incrementar o turismo na região do Parque Ambiental Encontro dos Rios. Segundo Lima, foram investidos cerca de setecentos mil reais nesse projeto. Cf. matéria disponível no site: http://www.pi.gov.br . Acesso em jul./2008.

${ }^{34}$ PELEGRINI, S. C. A. O patrimônio cultural e a materialização das memórias individuais e coletivas. Patrimônio e Memória. Assis: Unesp/CEDAP, 2007, v.1, n.1.

${ }^{35}$ SILVA, F. F. Mário e o patrimônio um anteprojeto ainda atual. Revista do Patrimônio Histórico e Artística Nacional, São Paulo, n. 30, pp.128 137, 2002.

${ }^{36}$ Para maiores detalhes, ver SJOTE, K. International legal protection of cultural heritage. Estocolmo: Jurist for Lagest, 1994; UNESCO. 
Declaration of the principles of international cultural co-operation, 1966; SILVA, F. F. Mário e o patrimônio um anteprojeto ainda atual. Revista do Patrimônio Histórico e Artística Nacional, Op. Cit.

37 Outros autores também comentam essa expansão do conceito de patrimônio: FONSECA, M. C. L. O patrimônio em processo. Trajetória da política federal de preservação no Brasil. Rio de Janeiro: Editora UFRJ/MInc/IPHAN, 1997; KERSTEN, M. S. A. Os rituais do Tombamento e a escrita da História: Bens Tombados no Paraná entre 1938 - 1990. Op. cit; PELEGRINI, S. C. A. O patrimônio cultural no discurso e na lei: trajetórias do debate sobre a preservação no Brasil. Patrimônio e Memória - Revista Eletrônica, Op. cit.; PELEGRINI, S. C. A. Cultura e Natureza: Os desafios das práticas preservacionistas na esfera do patrimônio cultural e ambiental. Revista Brasileira de História. São Paulo, v. 26, no. 51, p. 115-140, 2006.

${ }^{38}$ Cf. a "Conferência Mundial sobre as políticas culturais" (1982)

${ }^{39}$ Esse documento ficou conhecido também como "Nossa Diversidade Criativa" e pode ser considerado responsável pela ênfase à ordenação dos direitos culturais, antes disseminados apenas entre os instrumentos legais de proteção aos direitos humanos. A sugestão, pois, da realização de um inventário específico dos direitos culturais propiciou o reconhecimento formal do direito à difusão, à identidade cultural, à cooperação cultural internacional, à criação e participação na vida cultural e ao direito autoral (o primeiro deles reconhecido oficialmente).

40 Vale lembrarmos que a instituição legal do direito autoral esteve articulada aos ideais revolucionários eclodidos na Inglaterra (1688), Estados Unidos (1776) e França (1789), mobilizações que corroboraram para o reconhecimento da criação intelectual e artística como uma das mais autênticas propriedades individuais. PELEGRINI, S. C. A. e FUNARI, P. P. O que patrimônio cultural imaterial. Op. cit.

${ }^{41}$ ICOMOS, Recomendação sobre a salvaguarda da cultura tradicional e popular, 1989. Disponível em site: http://www.portal.iphan.gov.br . Acesso em out./2005.

42 Sobre o assunto consultar: BOURDIEU, P. Langage et pouvoir symbolique. Paris: Fayard, 2001; CHARTIER, R. Lo popular: entre desprecio y mercado, entre creencia y distancia. In: BARBOSA, M. H. S.; RETTENMAIER, M.; RÖSING, T. M. K.(org.). Leitura, identidade e patrimônio cultural. Passo Fundo: EPF Editora Universitária, 2004, pp. 15-31. 
${ }^{43}$ UNESCO. Convention for the Safeguarding of the Intangible Cultural Heritage (2003). Disponível em site: http://www.unesco.org . Acesso em jan./2005.

${ }^{44}$ Ainda assim, entendemos que a Convenção de 2003 não avançou em relação às proposições da "Recomendação sobre a salvaguarda da cultura tradicional e popular" (1989) e da "Declaração universal da Unesco sobre a diversidade cultural" (2001).

${ }^{45}$ UNESCO. Convention for the Safeguarding of the Intangible Cultural Heritage (2003). Op. cit.

${ }^{46} \mathrm{O}$ artigo quinto da Convenção estabelecia a criação de um comitê eleito em Assembléia Geral, entre os Estados-membros da Unesco. $\mathrm{Na}$ ocasião, foram escolhidos os senhores: Mohamed Bedjaui (da Argélia, como primeiro presidente); O. Faruk Logoglu (da Turquia) e quatro vice-presidentes oriundos do Brasil, Etiópia, Índia e Romênia. Entre os demais países que integraram o Comitê constavam representantes da Bélgica, Bulgária, China, Emirados Árabes Unidos, Estônia, Gabão, Hungria, Japão, México, Nigéria, Peru, Senegal, Vietnam, Madagascar, Albânia, Zâmbia, Armênia, Zimbabue, Camboja, a ex-República Yugoslava de Macedônia, Marrocos, França e Côte d'Ivoire.

${ }^{47}$ UNESCO. Convention on the protection and promotion of the diversity of cultural expressions, 2005. Disponível em site: http://www.unesco.org . Acesso em jul./2006.

${ }^{48}$ Esse tema, dado a sua complexidade, deverá ser tratado em outra oportunidade.

Artigo recebido em 10/2008. Aprovado em 11/2008. 


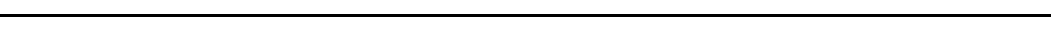

